\title{
Effect of surgical liver resection on circulating tumor cells in patients with hepatocellular carcinoma
}

\author{
Jing-jing Yu' ${ }^{1}$ Wei Xiao', Shui-lin Dong ${ }^{2}$, Hui-fang Liang ${ }^{2}$, Zhi-wei Zhang ${ }^{2}$, Bi-xiang Zhang ${ }^{2}$, Zhi-yong Huang ${ }^{2}$, \\ Yi-fa Chen ${ }^{2}$, Wan-guang Zhang ${ }^{2}$, Hong-ping Luo ${ }^{2}$, Qian Chen ${ }^{3}$ and Xiao-ping Chen ${ }^{1,2^{*}}$
}

\begin{abstract}
Background: This study explored the effect of liver resection on perioperative circulating tumor cells (CTCS) and found that the prognostic significance of surgery was associated with changes in CTC counts in patients with hepatocellular carcinoma (HCC).

Methods: One hundred thirty-nine patients with HCC were consecutively enrolled. The time-points for collecting blood were one day before operation and three days after operation. CTCS in the peripheral blood were detected by the CellSearch ${ }^{\text {TM }}$ System.

Results: Both CTC detection incidence and mean CTC counts showed greater increases postoperatively (54\%, mean 1.54 cells) than preoperatively (43\%, mean 1.13 cells). The postoperative CTC counts increased in $41.7 \%$ of patients, decreased in $25.2 \%$ of patients and did not change in $33.1 \%$ of patients. The increase in postoperative CTC counts was significantly associated with the macroscopic tumor thrombus status. Patients with increased postoperative CTC counts (from preoperative CTC $<2$ to postoperative $C T C \geq 2$ ) had significantly shorter disease-free survival (DFS) and overall survival (OS) than did patients with persistent $C T C<2$. Patients with persistent CTC levels of $\geq 2$ had the worst prognoses.
\end{abstract}

Conclusions: Surgical liver resection is associated with an increase in CTC counts, and increased postoperative CTC numbers are associated with a worse prognosis in patients with HCC.

Keywords: Circulating tumor cells, Perioperative period, Hepatocellular carcinoma, Liver resection, Disease-free survival, Overall survival

\section{Background}

Hepatocellular carcinoma (HCC) accounts for $90 \%$ of primary liver cancers and is the second most common cause of cancer-related deaths worldwide [1]. Currently, surgery is the first choice of treatment for this disease. Resection and liver transplantation achieve excellent results in early-stage patients [2], however, recurrence and metastasis are frequently seen post-resection, and approximately $40 \%$ of patients develop recurrences within the first year

\footnotetext{
* Correspondence: chenxpchenxp@163.com

${ }^{1}$ Translational Medicine Center, Tongji Hospital, Tongji Medical College, Huazhong University of Science and Technology, Wuhan 430030, People's Republic of China

${ }^{2}$ Hepatic Surgery Center, Tongji Hospital, Tongji Medical College, Huazhong University of Science and Technology, Wuhan 430030, China

Full list of author information is available at the end of the article
}

after hepatectomy [3]. Therefore, it is imperative to address those factors in the perioperative period that foster the capture and promotion of metastases to control residual malignant cells and improve long-term oncological outcomes.

Recent evidence has demonstrated that surgery, which is intended to be a curative option for removing and reducing the tumor mass to eliminate the cancer may increase the establishment of new metastases and accelerate growth of residual and micro-metastatic disease by generating a permissive environment for metastasis. This includes increased shedding of cancer cells into the bloodstream and suppressing antitumor immunity, thus allowing tumor cells to survive in the circulation [4-6]. However, whether surgical procedures introduce

(c) The Author(s). 2018 Open Access This article is distributed under the terms of the Creative Commons Attribution 4.0 International License (http://creativecommons.org/licenses/by/4.0/), which permits unrestricted use, distribution, and 
additional circulating tumor cells (CTCs) into the bloodstream remains controversial, as other studies have shown that CTC counts normalize and often decrease after surgery $[7,8]$. More importantly, the long-term effects that surgically released CTCs have on progression and survival remain unknown [9]. Several reports have demonstrated that increased postoperative CTC numbers were associated with worse prognoses in lung and colon cancers $[10,11]$, while one study on pancreatic cancer found no such relationship [12]. Therefore, diverse surgical operations for different solid cancers should be individually investigated, as the specific protocols of surgical tumor manipulation may be critical and may influence the outcomes.

Few data are available for evaluating possible modifications of CTC detection in the perioperative period of patients undergoing surgery for operable HCC. This study explored the effect of liver resection on perioperative CTCs and found that the prognostic significance of the surgery caused changes in CTC counts in patients with HCC. This information may increase our knowledge of the biology of the metastatic process, and particularly of the impact of surgery on the release of cells into the bloodstream.

\section{Methods}

\section{Patients}

One hundred thirty-nine patients with HCC and 23 control patients with benign hepatic tumors (cavernous hemangioma) were consecutively enrolled between December 2013 and June 2015 at the Hepatic Surgery Center, Tongji Hospital, Tongji Medical College, Huazhong University of Science and Technology. The inclusion criteria were (1) definitive pathological diagnosis of primary $\mathrm{HCC}$; (2) received curative resection, defined as complete macroscopic tumor removal; (3) margin-negative R0 resection; (4) no ablation used at the time of resection; (5) no prior anticancer treatment; and (6) aged between 18 and 80 years. Exclusion criteria were (1) with distant metastasis and (2) having other active or preexisting malignancies. All surgical procedures were performed in this department, and the same surgical and oncological principles were followed. The institutional review board approved the study protocol, and all patients provided written informed consent.

\section{CTC analysis}

Preoperative peripheral blood specimens were collected one day before surgery. To determine the postoperative time-point for blood collection, CTCs were detected in peripheral blood specimens collected immediately after surgery, three days after surgery and seven days after surgery in $12 \mathrm{HCC}$ patients (Additional file 1). Because the postoperative CTC counts showed no significant differences between the three time-points (Wilcoxon matched-paired signed rank test, $P>0.05$ ), three days after surgery was used as the postoperative time-point for collecting blood.

Briefly, peripheral blood specimens $(7.5 \mathrm{~mL})$ were drawn into CellSave Preservative Tubes (Janssen Diagnostics, LLC, Raritan, NJ, USA), stored at room temperature and processed within $96 \mathrm{~h}$ after collection. To avoid possible contamination with epithelial skin cells, one extra tube $(5 \mathrm{~mL})$ for other detections was filled before the assay tube. The CellSearch ${ }^{\mathrm{mm}}$ System was used for detecting and counting CTCs as previously described [13]. Briefly, tumor cells were immunomagnetically captured away from the peripheral blood cells using iron beads coated with anti-EpCAM monoclonal antibody (mAb) and then identified by fluorescence microscopy using the following definitions: cytokeratin-positive, CD45-negative, and nucleated.

\section{Statistical analysis}

Patients were followed until April 15, 2016. To be certain all deceased patients were counted, we reviewed the governmental death registration and made telephone follow-ups. Disease-free survival (DFS) and overall survival (OS) were estimated by Kaplan-Meier analysis and compared using the log-rank test. A Cox proportional hazards model was used to identify factors associated with DFS and OS, and those factors at $P<0.05$ in the univariate analysis were included in the multivariate models. A chi-squared test and Fisher's exact test were used for between-group comparisons as appropriate. $P<0.05$ was considered statistically significant. All statistical analyses were performed using SPSS version 21.0 for Windows (IBM).

\section{Results}

\section{Patient characteristics}

Table 1 summarizes the clinical demographics and tumor characteristics of the 139 patients with HCC enrolled in our study. The mean $( \pm \mathrm{SD})$ age of the patients was $49.9 \pm$ 10.3 years (range $24-77$ years), and $87.8 \%$ were male. Of these patients, $84.9 \%$ were hepatitis B surface antigen (HBsAg)-positive, and two were also positive for the hepatitis $\mathrm{C}$ virus $(\mathrm{HCV})$. Of these patients, $74.1 \%$ had liver cirrhosis, and $71.9 \%$ were $\alpha$-fetoprotein (AFP)-positive. Most patients (95.0\%) had normal hepatic function (Child-Pugh score A), and 7 who were classified as Child-Pugh score B received short-term liver protective therapy before surgery. Tumor stage was determined per the Barcelona Clinic Liver Cancer (BCLC) staging system. The proportion of stage $0+$ A was $40.3 \%$. 
Table 1 Clinical characteristics of 139 HCC patients

\begin{tabular}{|c|c|}
\hline Clinical characteristics & No. of patients \\
\hline \multicolumn{2}{|l|}{ Preoperative } \\
\hline Age, years & $\begin{array}{l}\text { Mean: } 49.9 \pm 10.3 \\
\text { Median: } 48.0\end{array}$ \\
\hline \multicolumn{2}{|l|}{ Sex } \\
\hline Male & 122 \\
\hline Female & 17 \\
\hline \multicolumn{2}{|l|}{$\mathrm{HBsAg}$} \\
\hline Negative & 21 \\
\hline Positive & 118 \\
\hline \multicolumn{2}{|l|}{ Liver cirrhosis } \\
\hline No & 36 \\
\hline Yes & 103 \\
\hline \multicolumn{2}{|l|}{ Child-Pugh score } \\
\hline A & 132 \\
\hline B & 7 \\
\hline \multicolumn{2}{|l|}{ Operative } \\
\hline \multicolumn{2}{|l|}{ Operation method } \\
\hline Open & 123 \\
\hline Laparoscopic & 16 \\
\hline Operation time (min) & $\begin{array}{l}\text { Mean: } 245.94 \pm 83.22 \\
\text { Median: } 236.00\end{array}$ \\
\hline Blood loss (ml) & $\begin{array}{l}\text { Mean: } 447.12 \pm 636.25 \\
\text { Median: } 200.00\end{array}$ \\
\hline \multicolumn{2}{|l|}{ Blood transfusion } \\
\hline Yes & 28 \\
\hline No & 111 \\
\hline \multicolumn{2}{|c|}{ Hepatic vascular occlusion } \\
\hline Yes & 83 \\
\hline No & 56 \\
\hline \multicolumn{2}{|l|}{ Tumor characteristics } \\
\hline \multicolumn{2}{|l|}{ Largest tumor size, $\mathrm{cm}$} \\
\hline$\leq 5$ & 61 \\
\hline$>5$ & 78 \\
\hline \multicolumn{2}{|l|}{ No. of tumors } \\
\hline Single & 106 \\
\hline Multiple & 33 \\
\hline \multicolumn{2}{|c|}{ Macroscopic tumor thrombus } \\
\hline No & 113 \\
\hline Yes & 26 \\
\hline \multicolumn{2}{|l|}{ Vascular invasion } \\
\hline No & 84 \\
\hline Yes & 55 \\
\hline \multicolumn{2}{|l|}{$\mathrm{BCLC}$ stage } \\
\hline $0+A$ & 56 \\
\hline$B+C$ & 83 \\
\hline
\end{tabular}

Table 1 Clinical characteristics of 139 HCC patients (Continued)

\begin{tabular}{ll}
\hline Clinical characteristics & No. of patients \\
\hline AFP, ng/mL & \\
Negative $(\leq 7.0)$ & 39 \\
Positive $(>7.0)$ & 100 \\
\hline
\end{tabular}

\section{Preoperative and postoperative CTC counts}

A comparison of the preoperative CTC counts for both the HCC and benign hepatic tumor patients is shown in Fig. 1a. Two of the 23 patients with benign hepatic tumors had $1 \mathrm{CTC}$; the remaining patients had 0 . The frequency distribution of preoperative and postoperative CTC counts in HCC patients was shown in Fig. 1b. The preoperative and postoperative CTC detection incidences were $43.9 \%$ and $54.0 \%$, respectively. The mean CTC counts also increased postoperatively (mean 1.54 cells, range $0-42$ cells) versus preoperatively (mean 1.13 cells, range $0-26$ cells), but the difference was not statistically significant (Wilcoxon matched-paired signed rank test, $P=0.1158)$. Ladder plots displayed preoperative and postoperative CTC counts for each of the $139 \mathrm{HCC}$ patients (Fig. 1c). Compared with the preoperative CTC counts, the postoperative CTC counts increased in 58 $(41.7 \%)$ patients, decreased in $35(25.2 \%)$ patients and did not change in 46 (33.1\%) patients (Fig. 1d).

The association between the change in perioperative CTC counts and HCC patient characteristics was analyzed. As shown in Table 2, the increase in postoperative CTC counts was significantly associated with the macroscopic tumor thrombus condition: CTCs increased postoperatively in $17 / 26(65.4 \%)$ patients with macroscopic tumor thrombus versus in $41 / 113$ (36.3\%) patients without macroscopic tumor thrombus $(P=$ 0.012). Postoperative CTC count changes were not significantly associated with age, sex, hepatitis B viral (HBV) infection, liver cirrhosis, Child-Pugh score, AFP, tumor size, tumor number, vascular invasion, BCLC stage, mode of operation (open or laparoscopic), operation duration, blood loss, blood transfusion or hepatic vascular occlusion during the operation.

\section{Prognostic significance of the surgery caused CTC count changes}

To investigate whether these perioperative CTC changes would have long-term effects on patients' DFS and OS, the CTC level was selected that most clearly distinguished patients with longer DFS and OS from those with shorter ones. The $139 \mathrm{HCC}$ patients in the cohort were randomly divided into two groups and analyzed, and their clinical characteristics and follow-up times did not significantly differ. The first group (training set, $n=72$ ) was then used to select the CTC cutoff level. Thresholds of 1 to 10 cells for the perioperative levels were systematically correlated 


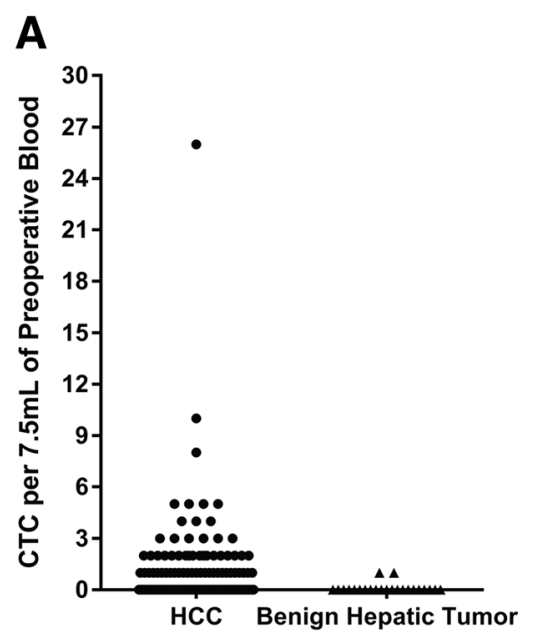

B
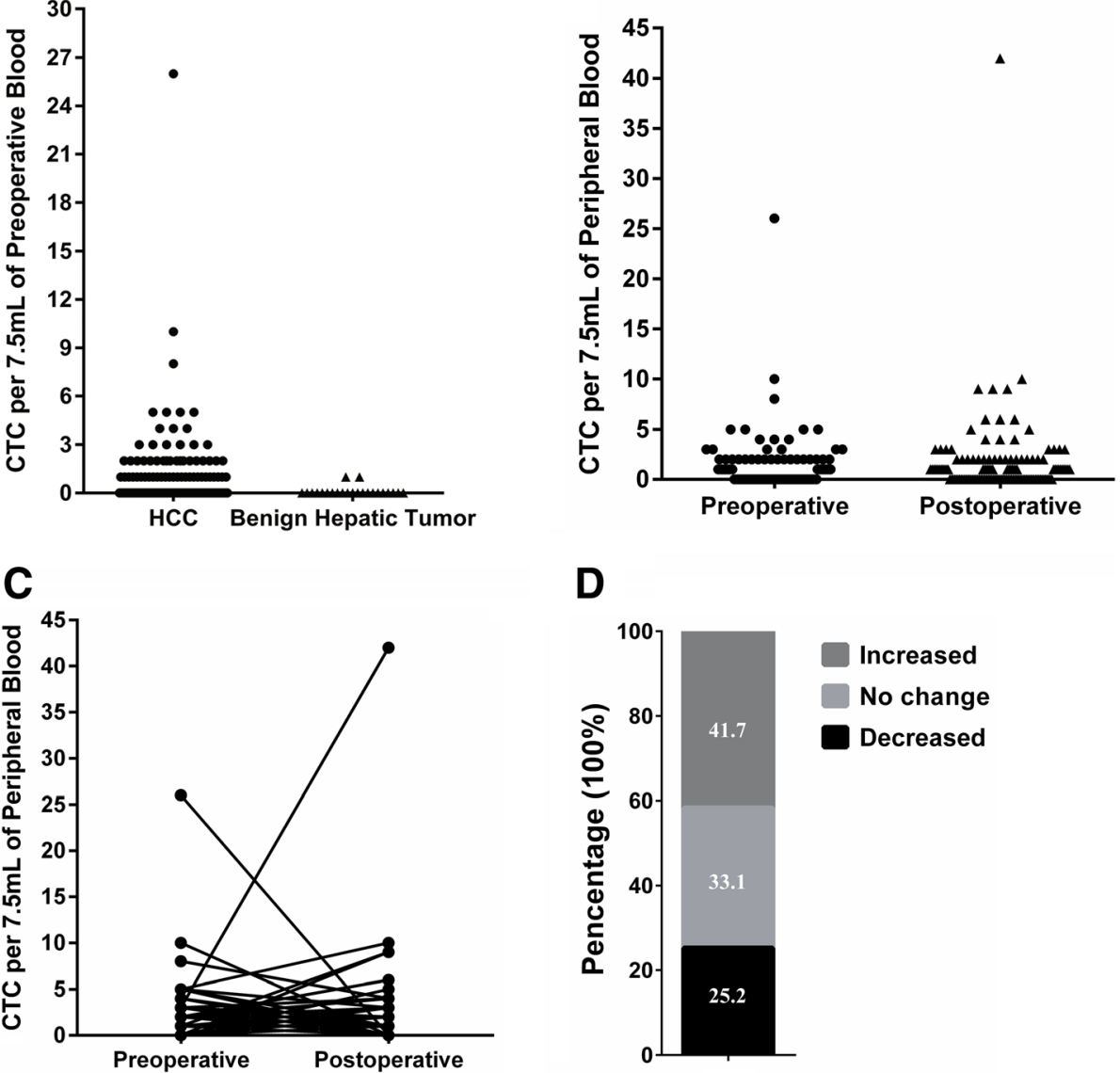

Fig. 1 Comparison of perioperative CTC counts in patients with HCC and benign hepatic tumors. a Frequency distribution of preoperative CTC counts in HCC and benign hepatic tumor patients; b Frequency distribution of preoperative and postoperative CTC counts in 139 HCC patients; $\mathbf{c}$ Ladder plots displaying preoperative and postoperative CTC counts for each HCC patient; $\mathbf{d}$ Incidence of increase, decrease or no change in the postoperative CTC counts relative to the preoperative CTC counts from the same HCC patient

with DFS and OS. The results indicated that in $7.5 \mathrm{ml}$ of blood, a threshold CTC value of 2 most significantly predicted patient outcome. This cutoff level was then validated using the second group (validation set, $n=67$ ). For both DFS (Fig. 2) and OS (Additional file 2), the Kaplan-Meier estimates for all patient sets differed significantly $(P<0.05)$; thus, a cutoff level of 2 was used for further analyses.

Next, using a CTC of 2 as the cutoff value, 139 HCC patients were divided into four groups (Fig. 3): I, persistent levels of $\geq 2$ CTC $(n=14)$; II, preoperatively $\geq 2$ then postoperatively <2 CTC $(n=20)$; III, preoperatively $<2$ then postoperatively $\geq 2$ CTC $(n=24)$; and IV, persistent levels of $<2$ CTC $(n=81)$. The tendency between DFS and OS did not significantly differ. Patients in group I showed worse prognoses than group IV, with significantly shorter DFS (median survival, 11.6 months versus not reached; $P<0.0001$ ) and $O S$ (median survival, 18.1 months versus not reached; death, $71.4 \%$ versus $7.4 \%$;
$P<0.0001)$. Group I also had an increased risk of death compared with group II (median survival, 18.1 months versus not reached; death, $71.4 \%$ versus $25.0 \% ; P=0.1082$ ) and group III (median survival, 18.1 months versus not reached; death, $71.4 \%$ versus $33.3 \%$; $P=0.1195$ ) in OS. Compared with group IV, patients in the other three groups had a significantly shorter DFS and OS $(P<0.05)$. Because patients in four groups showed significant differences in AFP, tumor size, tumor number, vascular invasion, macroscopic tumor thrombus and BCLC stage (Additional file 3), a multivariate Cox proportional regression analysis that included these factors was performed (to avoid potential bias, the BCLC stage was not included because it was associated with tumor characteristics and liver function). The results showed that this grouping was a strong independent predictor of DFS (HR, 0.620; 95\% CI: $0.479-0.803 ; P=0.000)$ and OS (HR, 0.608; 95\% CI: 0.443-0.834; $P=0.002$ ) (Table 3). Other tumor-related factors, including tumor size (DFS: 
Table 2 Relationship of perioperative CTC levels to patient characteristics

\begin{tabular}{|c|c|c|c|c|c|}
\hline \multirow[t]{2}{*}{ Characteristics } & \multicolumn{5}{|c|}{ Postoperative vs. Preoperative CTC counts } \\
\hline & Total $(N=139)$ & Decreased $(N=35)$ & No change $(N=46)$ & Increased $(N=58)$ & $P$ \\
\hline Age, years & & & & & 0.153 \\
\hline$\leq 50$ & 80 & 25 & 25 & 30 & \\
\hline$>50$ & 59 & 10 & 21 & 28 & \\
\hline Sex & & & & & 0.577 \\
\hline Male & 122 & 32 & 41 & 49 & \\
\hline Female & 17 & 3 & 5 & 9 & \\
\hline HBsAg & & & & & 0.521 \\
\hline Negative & 21 & 7 & 5 & 9 & \\
\hline Positive & 118 & 28 & 41 & 49 & \\
\hline Liver cirrhosis & & & & & 0.077 \\
\hline No & 36 & 13 & 7 & 16 & \\
\hline Yes & 103 & 22 & 39 & 42 & \\
\hline Child-Pugh score & & & & & $0.562^{*}$ \\
\hline A & 132 & 32 & 44 & 56 & \\
\hline B & 7 & 3 & 2 & 2 & \\
\hline Operation method & & & & & 0.408 \\
\hline Open & 123 & 33 & 39 & 51 & \\
\hline Laparoscopic & 16 & 2 & 7 & 7 & \\
\hline Operation time (min) & & & & & 0.247 \\
\hline$\geq 240$ & 68 & 21 & 19 & 28 & \\
\hline$<240$ & 71 & 14 & 27 & 30 & \\
\hline Blood loss (ml) & & & & & 0.313 \\
\hline$>200$ & 67 & 19 & 18 & 20 & \\
\hline$\leq 200$ & 72 & 16 & 28 & 28 & \\
\hline Blood transfusion & & & & & 0.318 \\
\hline Yes & 28 & 10 & 7 & 11 & \\
\hline No & 111 & 25 & 39 & 47 & \\
\hline Hepatic vascular occlusion & & & & & 0.211 \\
\hline Yes & 83 & 25 & 24 & 34 & \\
\hline No & 56 & 10 & 22 & 24 & \\
\hline AFP, ng/mL & & & & & 0.102 \\
\hline Negative $(\leq 7.0)$ & 39 & 5 & 16 & 18 & \\
\hline Positive (> 7.0) & 100 & 30 & 30 & 40 & \\
\hline Largest tumor size, $\mathrm{cm}$ & & & & & 0.067 \\
\hline$\leq 5$ & 61 & 10 & 25 & 26 & \\
\hline$>5$ & 78 & 25 & 21 & 32 & \\
\hline No. of tumors & & & & & 0.718 \\
\hline Single & 106 & 26 & 37 & 43 & \\
\hline Multiple & 33 & 9 & 9 & 15 & \\
\hline Macroscopic tumor thrombus & & & & & 0.012 \\
\hline No & 113 & 29 & 43 & 41 & \\
\hline Yes & 26 & 6 & 3 & 17 & \\
\hline
\end{tabular}


Table 2 Relationship of perioperative CTC levels to patient characteristics (Continued)

\begin{tabular}{|c|c|c|c|c|c|}
\hline \multirow[t]{2}{*}{ Characteristics } & \multicolumn{5}{|c|}{ Postoperative vs. Preoperative CTC counts } \\
\hline & Total $(N=139)$ & Decreased $(N=35)$ & No change $(N=46)$ & Increased $(N=58)$ & $P$ \\
\hline Vascular invasion & & & & & 0.053 \\
\hline No & 84 & 17 & 34 & 33 & \\
\hline Yes & 55 & 18 & 12 & 25 & \\
\hline BCLC stage & & & & & 0.089 \\
\hline $0+A$ & 56 & 10 & 24 & 22 & \\
\hline$B+C$ & 83 & 25 & 22 & 36 & \\
\hline
\end{tabular}

*Linear-by-linear association

HR, 4.840; 95\% CI: 1.518-15.428; $P=0.008$; OS: HR, 11.728; 95\% CI: 1.448-94.962; $P=0.021)$ and macroscopic tumor thrombus (DFS: HR, 2.588; 95\% CI: 1.174-5.706; $P=0.018$; OS: HR, 2.795; 95\% CI: $1.084-7.206 ; P=0.033$ ) remained significant and independent in the multivariate Cox regression. No other variables were included in the multivariate regression because they lacked significance in the univariate analysis.

\section{Discussion}

Surgical liver resection is the most effective therapy for early-stage HCC patients [14]. However, of the HCC patients undergoing surgery for resectable disease, more than 50\% will develop subsequent metastases [3]. The number of CTCs that the CellSearch ${ }^{\mathrm{Tm}}$ System detects in the vasculature has been shown to correlate with HCC patient survival and prognosis [8, 15]. However, using this technology for HCC is under debate as its CTC detection rate appears to associate with EpCAM expression in individual tumors [16]. EpCAM could serve as a biomarker for tumor-initiating cells in HCC [17], because EpCAM-positive CTCs are considered a subtype of circulating cancer stem cells with stronger metastatic potential. But only approximately $35 \%$ of HCC cases express EpCAM [18]; thus, detection sensitivity would be low and would include many false negative results. In this study, the detection ratios ( $\geq 1$ CTC) before and after surgery were $43.9 \%$ and $54.0 \%$, respectively, which

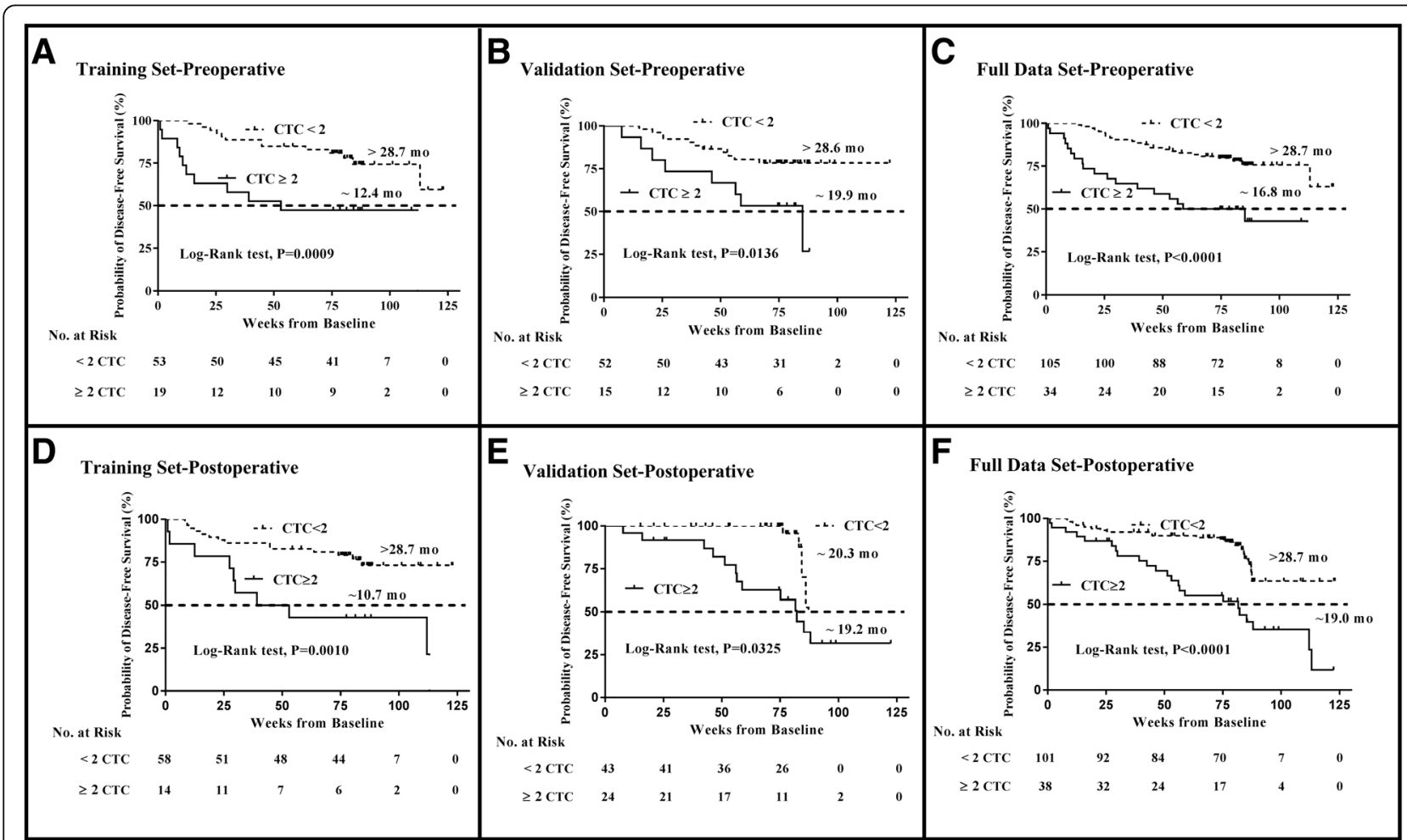

Fig. 2 Kaplan-Meier estimates of DFS probabilities in patients with operable HCC using a cutoff value of 2 CTCs per $7.5 \mathrm{ml}$ of peripheral blood. a Preoperative $\mathrm{CTC}<2$ or $\geq 2$, training set; $\mathbf{b}$ Preoperative $\mathrm{CTC}<2$ or $\geq 2$, validation set; $\mathbf{c}$ Preoperative $\mathrm{CTC}<2$ or $\geq 2$, full data set; $\mathbf{d}$ Postoperative CTC $<2$ or $\geq 2$, training set; e Postoperative $C T C<2$ or $\geq 2$, validation set; $\mathbf{f}$ Postoperative $C T C<2$ or $\geq 2$, full data set 

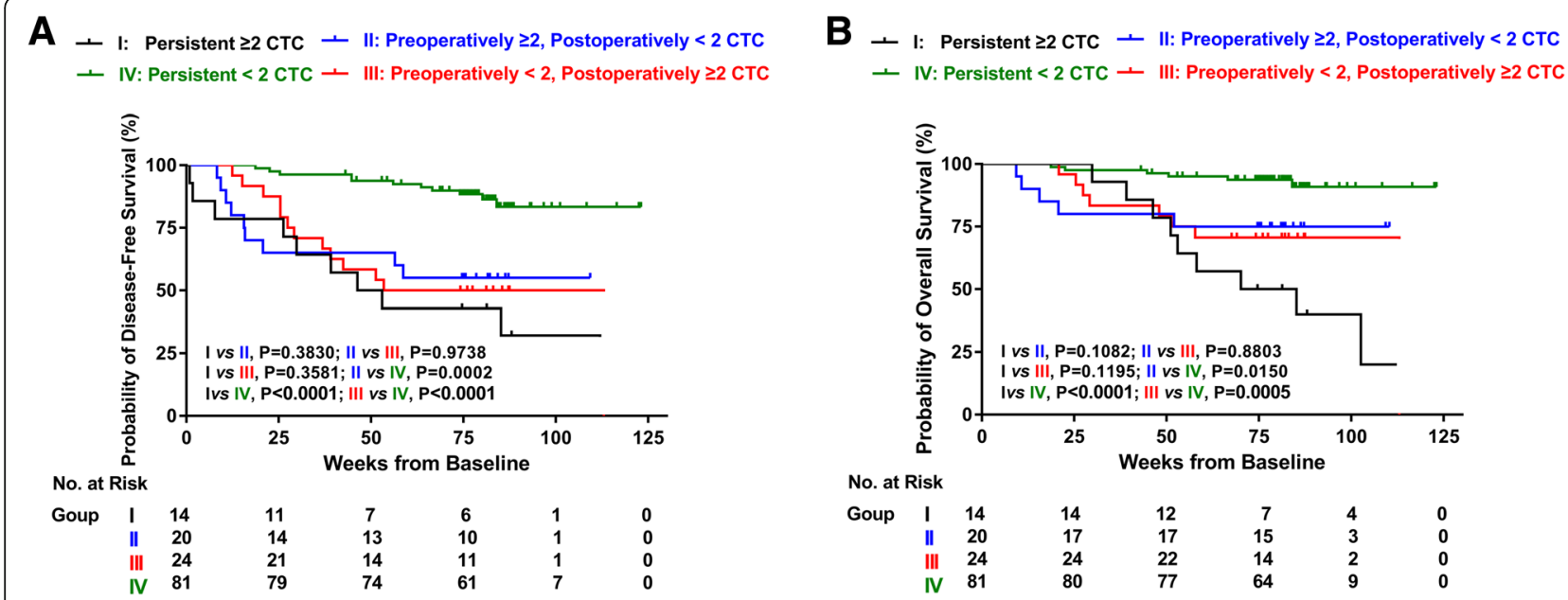

Fig. 3 Kaplan-Meier estimates of DFS and OS probabilities in HCC patients with persistent CTC $\geq 2$, change in CTCs from $\geq 2$ to $<2$, change in CTCs from $<2$ to $\geq 2$, and persistent $C T C<2$ before and after surgery

is consistent with previous reports and the EpCAM expression pattern in HCC $[8,15,19-22]$.

Many studies have shown that tumor biopsy and resection can lead to tumor cell dissemination [23, 24]. However, the impact of the increased CTCs remains controversial [9]. In our study, we found a propensity for increasing both the incidence of CTC detection and mean CTC counts postoperatively ( $54 \%$, mean 1.54 cells) versus preoperatively (43\%, mean 1.13 cells). The postoperative CTC counts increased in $41.7 \%$ of patients, decreased in $25.2 \%$ of patients and did not change in $33.1 \%$ of patients. The postoperative CTC counts changed (either increased or decreased) in $66.9 \%$ of HCC patients, indicating that surgery caused the CTC changes. The association between the change in perioperative
CTC counts and clinical parameters was analyzed next. We found that the increase in postoperative CTC counts was significantly associated with the macroscopic tumor thrombus condition, suggesting that carefully handling macroscopic tumor thrombi during the operation may reduce the number of CTCs released, thus improving patient outcomes.

Some evidence showed that HCC tended to spread from the portal system in the early stage and was driven into the blood stream from the hepatic vein tumor thrombus when moving and rotating the liver [25-27]. A "no-touch" technique might prevent the spread of cancer cells to vein during liver resection, which could reduce CTC dissemination [28]. Ligating inflow and outflow vessels without hilus dissection before manipulating

Table 3 Univariate and multivariate Cox proportional regression analysis of factors associating with DFS and OS

\begin{tabular}{|c|c|c|c|c|c|c|c|c|}
\hline \multirow[t]{3}{*}{ Variables } & \multicolumn{4}{|l|}{ Disease-free survival } & \multicolumn{4}{|l|}{ Overall survival } \\
\hline & \multicolumn{2}{|l|}{ Univariate analysis } & \multicolumn{2}{|l|}{ Multivariate analysis } & \multicolumn{2}{|l|}{ Univariate analysis } & \multicolumn{2}{|l|}{ Multivariate analysis } \\
\hline & $\mathrm{HR}(95 \% \mathrm{Cl})$ & $P$ & $\mathrm{HR}(95 \% \mathrm{Cl})$ & $P$ & $\mathrm{HR}(95 \% \mathrm{Cl})$ & $P$ & $\mathrm{HR}(95 \% \mathrm{Cl})$ & $P$ \\
\hline $\mathrm{Age}_{1}>50$ years vs. $\leq 50$ years & $0.739(0.398-1.373)$ & 0.339 & & & $0.466(0.207-1.054)$ & 0.067 & & \\
\hline Sex, male vs. female & $0.505(0.156-1.637)$ & 0.255 & & & $0.574(0.136-2.431)$ & 0.451 & & \\
\hline HBsAg, positive vs. negative & $2.528(0.780-8.192)$ & 0.122 & & & $4.966(0.673-36.617)$ & 0.116 & & \\
\hline Liver cirrhosis, yes vs. no & $0.568(0.303-1.065)$ & 0.078 & & & $0.799(0.362-1.765)$ & 0.580 & & \\
\hline Child-Pugh score, B vs. A & $1.398(0.430-4.543)$ & 0.577 & & & $1.977(0.590-6.624)$ & 0.269 & & \\
\hline No. of tumors, multiple vs. single & $2.287(1.209-4.327)$ & 0.011 & $0.939(0.475-1.855)$ & 0.856 & $3.223(1.505-6.902)$ & 0.003 & $1.379(0.618-3.078)$ & 0.432 \\
\hline Tumor size, $\leq 5 \mathrm{~cm}$ vs. $>5 \mathrm{~cm}$ & 10.403(3.710-29.173) & 0.000 & $4.840(1.518-15.428)$ & 0.008 & $27.058(3.679-199.020)$ & 0.001 & $11.728(1.448-94.962)$ & 0.021 \\
\hline $\begin{array}{l}\text { Macroscopic tumor thrombus, } \\
\text { yes vs. no }\end{array}$ & $6.836(3.567-13.100)$ & 0.000 & $2.588(1.174-5.706)$ & 0.018 & $8.194(3.646-18.413)$ & 0.000 & $2.795(1.084-7.206)$ & 0.033 \\
\hline Vascular invasion, yes vs. no & $6.145(3.124-12.085)$ & 0.000 & $1.816(0.766-4.307)$ & 0.176 & $5.933(2.584-13.622)$ & 0.000 & $1.491(0.510-4.357))$ & 0.466 \\
\hline AFP, positive vs. negative & $2.349(1.043-5.288)$ & 0.039 & $1.172(0.474-2.899)$ & 0.731 & $2.781(0.966-8.001)$ & 0.058 & $1.709(0.548-5.332)$ & 0.356 \\
\hline $\mathrm{BCLC}$ stage, $\mathrm{B}+\mathrm{C}$ vs. $0+\mathrm{A}$ & 8.695(3.103-24.370) & 0.000 & & & $11.212(2.663-47.204)$ & 0.001 & & \\
\hline Group & $0.529(0.414-0.676)$ & 0.000 & $0.620(0.479-0.803)$ & 0.000 & $0.484(0.357-0.656)$ & 0.000 & $0.608(0.443-0.834)$ & 0.002 \\
\hline
\end{tabular}


the tumor could completely block hepatic blood flow on the diseased side $[29,30]$. In our study, 5 patients with HCC used this technique, and none of them showed elevated CTCs postoperatively. Hence, operative modifications may reduce the occurrence of postoperative CTC increases, but studies of more patients with longer survival times are needed to confirm this.

Moreover, our data indicated that increased or decreased postoperative CTC counts were not significantly associated with patients' DFS or OS (data not shown), as both preoperative and postoperative CTC counts indicated patients' prognoses. We used a CTC count of 2 as the cutoff value. Patients with increased postoperative CTC counts (from preoperative CTC $<2$ to postoperative CTC $\geq 2$ ) had significantly shorter DFS and OS than did patients with persistent $\mathrm{CTC}<2$. Patients with persistent levels of $\geq 2$ CTC before and after surgery had the worst prognoses, while those with persistent levels of $<2$ CTC had the longest DFS and OS.

\section{Conclusions}

In conclusion, our data demonstrated the effect of surgical liver resection on CTCs in patients with HCC. Our findings supported the common occurrence of postoperative CTC increases but also indicated that this event may be prevented by operative modifications. These observations also suggested that detecting perioperative CTCs may be a strong indicator of the response to the HCC curative resection and therapeutic approach, which directly targets CTCs and could hold great promise as a perioperative adjuvant treatment.

\section{Additional files}

Additional file 1: Results of CTC detection at different time-points in 12 HCC patients undergoing curative liver resection. (DOCX 957 kb)

Additional file 2: Kaplan-Meier estimates of OS probabilities in patients with operable HCC using a cutoff value of 2 CTCs per $7.5 \mathrm{ml}$ of peripheral blood. (A) Preoperative CTC $<2$ or $\geq 2$, training set; (B) Preoperative CTC $<2$ or $\geq 2$, validation set; (C) Preoperative CTC $<2$ or $\geq 2$, full data set; (D) Postoperative CTC $<2$ or $\geq 2$, training set; (E) Postoperative $C T C<2$ or $\geq 2$, validation set; (F) Postoperative CTC $<2$ or $\geq 2$, full data set. (TIF $1682 \mathrm{~kb}$ )

Additional file 3: Baseline characteristics of HCC patients in four groups. (DOCX $1812 \mathrm{~kb}$ )

\section{Abbreviations}

AFP: a-fetoprotein; BCLC: Barcelona Clinic Liver Cancer; CTCs: circulating tumor cells; DFS: disease-free survival; HBsAg: hepatitis B surface antigen; HBV: hepatitis B virus; HCC: hepatocellular carcinoma; HCV: hepatitis C virus; OS: overall survival

\section{Funding}

This work was supported by the National Natural Science Foundation of China (81402087, 81372495, 81572855), the National Key Research and Development Program of China (2016YFC0106004) and the State Key Project on Infection Diseases of China (2012ZX10002010-001-004).

\section{Availability of data and materials}

The datasets used and analyzed during the current study are available from the corresponding author upon reasonable request.

\section{Authors' contributions}

JJY detected and identified CTCS, and was a major contributor in writing the manuscript. WX and SLD collected, analyzed and interpreted the patient data. HFL and HPL obtained the blood samples and detected CTCs too. ZWZ, BXZ, $Z Y H, Y F C$ and WGZ managed patients which included recruiting patients, performing operations and making follow-up. QC and XPC designed the experiment and modified the manuscript. All authors read and approved the final manuscript.

Ethics approval and consent to participate

The ethics committee of Tongji Hospital of Tongji Medical College of Huazhong University of Science and Technology approved the study protocol, and all patients provided written informed consent.

\section{Consent for publication}

Not applicable.

\section{Competing interests}

The authors declare that they have no competing interests

\section{Publisher's Note}

Springer Nature remains neutral with regard to jurisdictional claims in published maps and institutional affiliations.

\section{Author details}

${ }^{1}$ Translational Medicine Center, Tongji Hospital, Tongji Medical College, Huazhong University of Science and Technology, Wuhan 430030, People's Republic of China. ${ }^{2}$ Hepatic Surgery Center, Tongji Hospital, Tongji Medical College, Huazhong University of Science and Technology, Wuhan 430030, China. ${ }^{3}$ Division of Gastroenterology, Department of Internal Medicine, Tongji Hospital, Tongji Medical College, Huazhong University of Science and Technology, Wuhan 430030, China.

Received: 13 April 2018 Accepted: 13 August 2018

Published online: 20 August 2018

References

1. Torre LA, Bray F, Siegel RL, Ferlay J, Lortet-Tieulent J, Jemal A. Global cancer statistics, 2012. CA Cancer J Clin. 2015:65(2):87-108.

2. de Lope CR, Tremosini S, Forner A, Reig M, Bruix J. Management of HCC. J Hepatol. 2012;56(Suppl 1):S75-87.

3. Fan ST, Mau Lo C, Poon RT, Yeung C, Leung Liu C, Yuen WK, et al. Continuous improvement of survival outcomes of resection of hepatocellular carcinoma: a 20-year experience. Ann Surg. 2011;253(4):745-58.

4. Demicheli R, Retsky MW, Hrushesky WJ, Baum M, Gukas ID. The effects of surgery on tumor growth: a century of investigations. Ann Oncol. 2008; 19(11):1821-8

5. Tohme S, Simmons RL, Tsung A. Surgery for Cancer: a trigger for metastases. Cancer Res. 2017;77(7):1548-52.

6. Horowitz M, Neeman E, Sharon E, Ben-Eliyahu S. Exploiting the critical perioperative period to improve long-term cancer outcomes. Nat Rev Clin Oncol. 2015;12(4):213-26.

7. Kaifi JT, Li G, Clawson G, Kimchi ET, Staveley-O'Carroll KF. Perioperative circulating tumor cell detection: current perspectives. Cancer Biol Ther. 2016;17(8):859-69.

8. Sun YF, Xu Y, Yang XR, Guo W, Zhang X, Qiu SJ, et al. Circulating stem celllike epithelial cell adhesion molecule-positive tumor cells indicate poor prognosis of hepatocellular carcinoma after curative resection. Hepatology. 2013:57(4):1458-68

9. Marshall JR, King MR. Surgical intervention and circulating tumor cell count: a commentary. Transl Cancer Res. 2016:5(Suppl 1):S126-8.

10. Guller U, Zajac P, Schnider A, Bösch B, Vorburger S, Zuber M, et al. Disseminated single tumor cells as detected by real-time quantitative polymerase chain reaction represent a prognostic factor in patients undergoing surgery for colorectal cancer. Ann Surg. 2002;236(6):768-75. discussion 775-6 
11. Dong Q, Huang J, Zhou Y, Li L, Bao G, Feng J, et al. Hematogenous dissemination of lung cancer cells during surgery: quantitative detection by flow cytometry and prognostic significance. Lung Cancer. 2002;37(3):293-301.

12. Sergeant G, Roskams T, van Pelt J, Houtmeyers F, Aerts R, Topal B. Perioperative cancer cell dissemination detected with a real-time RT-PCR assay for EpCAM is not associated with worse prognosis in pancreatic ductal adenocarcinoma. BMC Cancer. 2011;11:47.

13. Yang JD, Campion MB, Liu MC, Chaiteerakij R, Giama NH, Ahmed Mohammed $\mathrm{H}$, et al. Circulating tumor cells are associated with poor overall survival in patients with cholangiocarcinoma. Hepatology. 2016;63(1):148-58.

14. Knox JJ, Cleary SP, Dawson LA. Localized and systemic approaches to treating hepatocellular carcinoma. J Clin Oncol. 2015;33(16):1835-44.

15. Schulze K, Gasch C, Staufer K, Nashan B, Lohse AW, Pantel K, et al. Presence of EpCAM-positive circulating tumor cells as biomarker for systemic disease strongly correlates to survival in patients with hepatocellular carcinoma. Int J Cancer. 2013;133(9):2165-71.

16. Went PT, Lugli A, Meier S, Bundi M, Mirlacher M, Sauter G, et al. Frequent EpCam protein expression in human carcinomas. Hum Pathol. 2004;35(1):122-8.

17. Yamashita T, Ji J, Budhu A, Forgues M, Yang W, Wang HY, et al. EpCAMpositive hepatocellular carcinoma cells are tumor-initiating cells with stem/ progenitor cell features. Gastroenterology. 2009;136(3):1012-24.

18. Yamashita T, Forgues M, Wang W, Kim JW, Ye Q, Jia H, et al. EpCAM and alpha-fetoprotein expression defines novel prognostic subtypes of hepatocellular carcinoma. Cancer Res. 2008;68(5):1451-61.

19. Sanchez-Lorencio MI, Ramirez P, Saenz L, Martínez Sánchez MV, De La Orden V, Mediero-Valeros B, et al. Comparison of two types of liquid biopsies in patients with hepatocellular carcinoma awaiting Orthotopic liver transplantation. Transplant Proc. 2015;47(9):2639-42.

20. $\mathrm{Mu} \mathrm{H}$, Lin $\mathrm{KX}$, Zhao H, Xing S, Li C, Liu F, et al. Identification of biomarkers for hepatocellular carcinoma by semiquantitative immunocytochemistry. World J Gastroenterol. 2014;20(19):5826-38.

21. Kelley RK, Magbanua MJ, Butler TM, Collisson EA, Hwang J, Sidiropoulos N, et al. Circulating tumor cells in hepatocellular carcinoma: a pilot study of detection, enumeration, and next-generation sequencing in cases and controls. BMC Cancer. 2015;15:206.

22. Morris KL, Tugwood JD, Khoja L, Lancashire M, Sloane R, Burt D, et al. Circulating biomarkers in hepatocellular carcinoma. Cancer Chemother Pharmacol. 2014;74(2):323-32.

23. Nishizaki T, Matsumata T, Kanematsu T, Yasunaga C, Sugimachi K. Surgical manipulation of VX2 carcinoma in the rabbit liver evokes enhancement of metastasis. J Surg Res. 1990;49(1):92-7.

24. Hashimoto M, Tanaka F, Yoneda K, Takuwa T, Matsumoto S, Okumura Y, et al. Significant increase in circulating tumour cells in pulmonary venous blood during surgical manipulation in patients with primary lung cancer. Interact Cardiovasc Thorac Surg. 2014;18(6):775-83.

25. Yamanaka N, Okamoto E, Fujihara S, Kato T, Fujimoto J, Oriyama T, et al. Do the tumor cells of hepatocellular carcinomas dislodge into the portal venous stream during hepatic resection? Cancer. 1992;70(9):2263-7.

26. Yamanaka N, Okamoto E, Toyosaka A, Mitunobu M, Fujihara S, Kato T, et al. Prognostic factors after hepatectomy for hepatocellular carcinomas. A univariate and multivariate analysis. Cancer. 1990;65(5):1104-10.

27. Koo J, Fung K, Siu KF, Lee NW, Lett Z, Ho J, et al. Recovery of malignant tumor cells from the right atrium during hepatic resection for hepatocellular carcinomas. Cancer. 1983;52(10):1952-6.

28. Atkin G, Chopada A, Mitchell I. Colorectal cancer metastasis: in the surgeon's hands? Int Semin Surg Oncol. 2005;2(1):5.

29. Chen XP, Qiu FZ. A simple technique ligating the corresponding inflow and outflow vessels during anatomical left hepatectomy. Langenbeck's Arch Surg. 2008;393(2):227-30. discussion 231-4

30. Chen XP, Zhang ZW, Huang ZY, Chen YF, Zhang WG, Qiu FZ. Alternative managenment of anatomical right hemihepatectomy using ligation of inflow and outflow vessels without hilus dissection. J Gastroenterol Hepatol. 2011;26(4):663-8.

Ready to submit your research? Choose BMC and benefit from:

- fast, convenient online submission

- thorough peer review by experienced researchers in your field

- rapid publication on acceptance

- support for research data, including large and complex data types

- gold Open Access which fosters wider collaboration and increased citations

- maximum visibility for your research: over $100 \mathrm{M}$ website views per year

At $\mathrm{BMC}$, research is always in progress.

Learn more biomedcentral.com/submissions 